\title{
Molecular detection of vector-borne pathogens in dogs and cats from Qatar
}

Ana Margarida Alho', Clara Lima², Maria Stefania Latrofa ${ }^{3}$, Vito Colella ${ }^{3}$, Silvia Ravagnan ${ }^{4}$, Gioia Capelli ${ }^{4}$, Luís Madeira de Carvalho ${ }^{1}$, Luís Cardoso $0^{5}$ and Domenico Otranto ${ }^{3^{*}}$

\begin{abstract}
Background: Vector-borne diseases (VBDs) have been increasingly reported in dogs and cats worldwide. However, no data are currently available regarding canine and feline VBDs in Qatar and limited information is available from other Persian Gulf countries.

Methods: Blood samples from 98 client-owned animals (i.e. 64 dogs and 34 cats) living in Doha (Qatar) were collected and the presence of genomic DNA of Anaplasma spp., Babesia spp., Dirofilaria spp., Ehrlichia spp., Hepatozoon spp., Mycoplasma spp. and Rickettsia spp. was assessed by polymerase chain reaction (PCR), real time-PCR (rt-PCR) and sequence analysis.
\end{abstract}

Results: Of the 64 dogs, 12 (18.8\%) were infected with at least one pathogen (i.e. 7.8\% with Mycoplasma spp., 4.7\% with Babesia vogeli, 3.1\% with Ehrlichia canis, and 1.6\% with Anaplasma platys, Babesia gibsoni and Hepatozoon canis, each). One of the 12 dogs was co-infected with B. vogeli and E. canis. Of the 34 cats, seven (20.6\%) animals were infected with at least one pathogen (i.e. 5.9\% were positive for Mycoplasma spp., and 2.9\% for Babesia felis, B. vogeli, E. canis, "Candidatus Mycoplasma haemominutum" and Mycoplasma haemofelis, each). No dogs or cats were positive for Dirofilaria spp. or Rickettsia spp.

Conclusions: Although the sample sizes of dogs and cats herein analysed was moderately small, data from this study report the occurrence of A. platys, B. vogeli, B. gibsoni, E. canis, H. canis and Mycoplasma spp. in domestic dogs and of B. felis, B. vogeli, "Candidatus M. haemominutum", E. canis and M. haemofelis in domestic cats from Qatar. Further investigations along with prophylactic measures are strongly recommended in order to reduce the risk of dogs and cats acquiring VBDs in Qatar.

Keywords: Anaplasma platys, Babesia felis, Babesia gibsoni, Babesia vogeli, Ehrlichia canis, Hepatozoon canis, Mycoplasma spp., Dogs, Cats, Qatar

\section{Background}

Canine and feline vector-borne diseases (VBDs) are caused by a wide range of pathogens, comprising viruses, bacteria, protozoa and helminths, transmitted to dogs and cats by different species of arthropod vector [1]. Some of these pathogens may represent a serious threat to animal health and welfare, and constitute a diagnostic challenge to practitioners due to the wide spectrum of clinical manifestations, the long prepatent periods and the frequent occurrence of co-infections [2]. For instance, pathogens belonging to the genera Anaplasma, Babesia,

\footnotetext{
* Correspondence: domenico.otranto@uniba.it

${ }^{3}$ Dipartimento di Medicina Veterinaria, Università degli Studi di Bari, Bari, Italy Full list of author information is available at the end of the article
}

Ehrlichia, Hepatozoon and Rickettsia cause tick-borne diseases of major concern in dogs and cats [3-6].

Nowadays, VBDs are increasingly reported in several regions of Europe [7, 8]. Recent studies have reported that demographic and political changes, increased global transport, deforestation, urbanization, abundance of wildlife hosts, climate alterations and the availability of more accurate diagnostic tools may have accounted for this expansion [8-10]. In Europe there are reports of canine VBDs spreading to non-endemic countries; examples include dirofilariosis caused by Dirofilaria immitis and Dirofilaria repens, which is spreading to northern and Eastern Europe [11], and babesiosis caused by Babesia canis which is extending towards northern European countries [12, 13]. Nonetheless, 
the scant investigation of vector-borne pathogens (VBPs) may underestimate their prevalence and distribution in several countries. This is the case of Qatar, a country located in the northern hemisphere desert, Middle East, bordering Saudi Arabia. In recent years, as a result of massive immigration, Qatar has experienced a rapid demographic growth and a concomitant increase in the number of pets. These factors, along with the documented population's shift from the rural areas to populated urban centres like Doha, have enhanced the risk of exotic VBDs [14].

As no data are available regarding VBDs and associated pathogens in cats and dogs from Qatar, a comprehensive molecular survey was conducted to assess the occurrence of agents belonging to the genera Anaplasma, Babesia, Dirofilaria, Ehrlichia, Hepatozoon, Mycoplasma and Rickettsia in dogs and cats from Doha.

\section{Methods}

\section{Study location}

Qatar has a desert climate with an arid and hot summer characterized by temperatures ranging between 25 and $46{ }^{\circ} \mathrm{C}$, and a relatively mild winter, with minimal rainfall. Doha is the country's capital and its largest city.

\section{Animals sampling}

From March to July 2016, 98 randomly enrolled owned pets (i.e. 64 dogs and 34 cats) living in Doha city and its outskirts were presented to a veterinary medical centre in Doha for routine procedures (animals were clinically healthy). Overall, 39 male and 25 female dogs, with ages ranging from 2 months to 13 years (median: 24 months) were examined. Almost half were mixed-breeds $(n=33$; $51.6 \%)$ and the other half pure breeds $(n=31 ; 48.4 \%)$. Fifty dogs (78.1\%) were born in Qatar and had no history of travelling, whereas the remaining $(n=14 ; 21.9 \%)$ were imported from a range of countries (e.g. Oman, UK, United Arab Emirates, USA and the Ukraine).

Of the enrolled cats, 23 were males and 11 were females, with ages ranging from 6 months to 13 years (median: 24 months). All cats were from pure breeds (domestic short-haired, domestic long-haired, Persian and Himalayan). Nine cats were exclusively kept indoors and the remaining 25 had outdoor access; 32 were born in Qatar and had no history of travelling abroad, while two were imported, one from South Africa and the other from the Ukraine. Ectoparasites (only tick specimens) were detected in nine animals ( $n=6$ dogs; $n=3$ cats), although not collected for the present study.

Whole blood was collected from each animal by venipuncture of the cephalic and/or jugular veins. Two drops of whole blood $(\sim 80 \mu \mathrm{l})$ were spotted onto the centre of two separate filter papers, air-dried for 3-4 h and individually stored in a sterile bag at $-20{ }^{\circ} \mathrm{C}$.

\section{Molecular procedures and pathogens investigated}

Genomic DNA was extracted from the filter papers using a commercial kit (QIAampDNA Micro Kit, Qiagen, Hilden, Germany), according to the manufacturer's instructions. DNA of Anaplasma spp., Ehrlichia spp., Hepatozoon spp. and Dirofilaria spp. was detected by conventional PCR (cPCR) using primers targeting partial 16S rRNA, 18S rRNA and cytochrome $c$ oxidase subunit 1 (cox 1$)$ genes (350, 600 and 689 bp, respectively) and protocols described elsewhere [15-17]. DNA of Mycoplasma spp. was detected using SYBR Green real-time PCR (rt-PCR) assay by amplification of two fragments for $16 \mathrm{~S}$ rRNA gene of different size (i.e. 127 and $259 \mathrm{bp}$ ) as described elsewhere [18, 19], whilst Rickettsia spp. was detected using SYBR Green rt-PCR assay by amplification of rompB (489 bp) gene, as previously described [20]. Blood samples were also tested for Babesia spp. and Theileria spp. (18S rRNA), both by cPCR (410 bp) and rt-PCR (411-452 bp) [21, 22]. For all PCR tests, positive (DNA of a pathogen-positive blood sample) and negative (no DNA) controls were included. PCR products were examined on 2\% agarose gels stained with GelRed (VWR International, Milano, Italy) and visualized on a GelLogic 100 gel documentation system (Kodak, New York, USA). The amplicons were purified and sequenced in both directions using the same primers as for PCR, employing the Big Dye Terminator v.3.1 chemistry in a 3130 Genetic Analyzer (Applied Biosystems, Foster City, CA, USA). Sequences were aligned using the ClustalW program [23] and molecular identification achieved by comparison with those available in the GenBank database by the Basic Local Alignment Search Tool (BLAST; http://blast.ncbi.nlm.nih.gov/Blast.cgi).

\section{Data analysis}

Exact binomial 95\% confidence intervals (CI) were established for proportions. The Chi-square and Fisher's exact tests were used to compare proportions, with a probability $P$-value $<0.05$ regarded as statistically significant. Analyses were done using the StatLib software.

\section{Results}

Out of the 64 dogs tested, 12 (18.8\%) were positive for at least one pathogen. Five (7.8\%) dogs were positive for Mycoplasma spp. (not identified to the species level by sequencing), three (4.7\%) for Babesia vogeli, two (3.1\%) for Ehrlichia canis, and one (1.6\%) for Anaplasma platys, Babesia gibsoni and Hepatozoon canis, each. Co-infection with two pathogens (i.e. B. vogeli+E. canis) was molecularly detected in one $\operatorname{dog}(1.6 \%)$ (Table 1 ).

Seven out of 34 cats $(20.6 \%)$ were positive for one of the detected vector-borne pathogens. Two cats (5.9\%) were positive for Mycoplasma spp., and one (2.9\%) for Babesia 
Table 1 Prevalence, accession number and percentage of nucleotide identity of vector-borne pathogens detected in 64 dogs from Doha (Qatar)

\begin{tabular}{|c|c|c|c|c|}
\hline \multirow[t]{2}{*}{ Pathogen } & \multicolumn{3}{|c|}{ Positive dogs } & \multirow{2}{*}{$\begin{array}{l}\text { Accession number, } \\
\text { percentage of nucleotide } \\
\text { identity }\end{array}$} \\
\hline & $n$ & $\%$ & $95 \% \mathrm{Cl}$ & \\
\hline Single infections & 11 & 17.2 & $8.9-28.7$ & \\
\hline Anaplasma platys & 1 & 1.6 & $0.0-8.4$ & KU500914; 100\% \\
\hline Babesia gibsoni & 1 & 1.6 & $0.0-8.4$ & KP666166; 100\% \\
\hline Babesia vogeli & 2 & 3.1 & $0.4-10.8$ & KU662366, KT333456; 100\% \\
\hline Ehrlichia canis & 1 & 1.6 & $0.0-8.4$ & KR920044; 100\% \\
\hline Hepatozoon canis & 1 & 1.6 & $0.0-8.4$ & KJ605145; 100\% \\
\hline Mycoplasma spp. & 5 & 7.8 & $2.6-17.3$ & ns \\
\hline Co-infections & 1 & 1.6 & $0.0-8.4$ & \\
\hline B. vogeli + E. canis & 1 & 1.6 & $0.0-8.4$ & \\
\hline Single + co-infections ( $\geq 1$ agent) & 12 & 18.8 & $10.1-30.5$ & \\
\hline
\end{tabular}

Abbreviations: $95 \% \mathrm{Cl}$, 95\% confidence interval; $n s$, not sequenced

felis, B. vogeli, E. canis, "Candidatus Mycoplasma haemominutum" and Mycoplasma haemofelis, each (Table 2).

BLAST analysis confirmed the pathogen identification with the highest nucleotide identity (i.e. $99-100 \%$, Tables 1 and 2) with the sequences available in the GenBank database (accession numbers: AY452707; KJ605145; KP666166; KR920044; KT333456, KU500914; KU645929; KU645935; KU662366). No animal was positive for Dirofilaria spp. and Rickettsia spp.

No statistically significant associations were found for positivity to VBPs among the categories of gender ( $P=0.728)$, juvenile vs adult $(P=0.240)$, pure vs mixedbreeds $(P=1.0)$, born in vs out of Qatar $(P=0.437)$, or indoor vs outdoor lifestyle $(P=1.0)$. All representative sequences obtained are available in the GenBank database under accession numbers: MF140995-MF140999 and MF142765-MF142769.

\section{Discussion}

Data obtained from this study indicate that dogs and cats from Doha city, Qatar, are infected with several VBPs, which have been identified by sequence analysis.
Indeed, although the sample sizes of dogs and cats herein analysed was small, the occurrence of $A$. platys, B. vogeli, B. gibsoni, E. canis, H. canis and Mycoplasma spp. have been recorded in domestic dogs; and of B. felis, B. vogeli, "Candidatus M. haemominutum", E. canis and $M$. haemofelis in domestic cats. Results show that approximately one fifth of the dogs (18.8\%) and cats $(20.6 \%)$ are infected with tick-borne pathogens, taking into account that all the detected agents are vectored or potentially vectored by ticks. This finding is of relevance considering that sampled animals are client-owned pets and may underrepresent the overall population, including stray animals.

Haemotropic mycoplasmas were the most prevalent VBPs detected in this study. Few data are available on the status of hemoplasmas in the Middle East, with one study showing the presence of the three feline species or candidate species (M. haemofelis, "Candidatus M. haemominutum" and "Candidatus Mycoplasma turicensis") in Iranian cats [24]. In the present study, M. haemofelis and "Candidatus M. haemominutum" were detected in cats from Qatar, and Mycoplasma spp. was found in

Table 2 Prevalence, accession number and percentage of nucleotide identity of vector-borne pathogens detected in 34 cats from Doha (Qatar)

\begin{tabular}{|c|c|c|c|c|}
\hline \multirow[t]{2}{*}{ Pathogen } & \multicolumn{3}{|c|}{ Positive cats } & \multirow{2}{*}{$\begin{array}{l}\text { Accession number, percentage } \\
\text { of nucleotide identity }\end{array}$} \\
\hline & $\bar{n}$ & $\%$ & $95 \% \mathrm{Cl}$ & \\
\hline Babesia felis & 1 & 2.9 & $0.1-15.3$ & AY452707; 99\% \\
\hline Babesia vogeli & 1 & 2.9 & $0.1-15.3$ & КT333456; 100\% \\
\hline Ehrlichia canis & 1 & 2.9 & $0.1-15.3$ & KR920044, 100\% \\
\hline Mycoplasma spp. & 2 & 5.9 & $0.7-19.7$ & ns \\
\hline Mycoplasma haemofelis & 1 & 2.9 & $0.1-15.3$ & KU645929; 99\% \\
\hline "Candidatus Mycoplasma haemominutum" & 1 & 2.9 & $0.1-15.3$ & KU645935; 99\% \\
\hline Single infections & 7 & 20.6 & $8.7-37.9$ & \\
\hline
\end{tabular}

Abbreviations: 95\% Cl, 95\% confidence interval; ns, not sequenced 
dogs, thereby expanding the current knowledge of the distribution of feline and canine hemoplasmosis in the Middle East. The occurrence of $A$. platys and E. canis in dogs has been previously reported in the Middle East region, specifically in dogs from Turkey [25], and of Ehrlichia spp. from Saudi Arabia [26]. Additionally, in Israel and Egypt dogs were found to have antibodies to E. canis [27-29], whereas antibodies to Anaplasma spp. have been demonstrated only by immunofluorescence antibody tests in domestic dogs [29]. Conversely, canine hepatozoonosis caused by $H$. canis has been reported several times from regions of the Middle East, particularly in Israel [30], Iraq [31] and Egypt [32]. In the present study, three distinct species of Babesia were detected in Qatar, namely B. felis, B. gibsoni and B. vogeli. Although the virulence of these intraerythrocytic protozoans varies among species, $B$. gibsoni is known to cause highly severe disease [33] and may represent a serious threat for dogs living in Qatar. Babesia felis was here identified in a cat imported from South Africa, where clinical babesiosis has been reported in domestic cats [34]. Except for B. felis, all the detected agents were found in pets that had never travelled outside of Qatar, suggesting that these infections were locally acquired and that these pathogens are endemic in Doha.

Most of the detected pathogens are vectored or suspect to be vectored by Rhipicephalus sanguineus (sensu lato), a tick species displaying a worldwide geographical distribution, a vast competency to transmit pathogens and a great adaptability to survive in distinct ecosystems [1, 35]. However, no information is available on its occurrence in Qatar, only in nearby countries such as Saudi Arabia and the United Arab Emirates [26, 36].

The lack of epidemiological studies in the Arabian Peninsula prevents any speculation on the impact of VBPs on the health of dogs and cats. However, the hot and arid climate of Qatar has shown to be potentially suitable to the perpetuation of vectors and transmission of several arthropod-borne diseases. The ascending development of Qatar's economy has led to an inflow and outflow of people and their pets. This factor may lead to an increase risk of introduction and spreading of VBPs. Therefore, effective prophylaxis, as well as routine screenings should be advocated in pets from Qatar. Diagnostic screenings should also be performed when formulating Pet Travel Schemes of animals relocating to and from the Middle East region.

\section{Conclusions}

This study expands the information on the distribution of canine and feline VBPs in dogs and cats inhabiting Qatar. Further studies, including a larger number of pets and populations from other areas are needed to better understand the epidemiological scenario of VBDs in the country. Considering the impact of such diseases on the health of cats and dogs, routine screenings and prophylactic measures are strongly recommended.

\section{Abbreviations}

PCR: Polymerase chain reaction; rt-PCR: Real-time PCR; VBDs: Vector-borne diseases; VBPs: Vector-borne pathogens

\section{Acknowledgements}

This publication has been sponsored by Bayer Animal Health in the framework of the 12th CVBD World Forum Symposium.

\section{Funding}

This study was financially supported by Fundação para a Ciência e a Tecnologia (FCT), through the Project UID/CVT/00276/2013 (CIISA, FMV, Universidade de Lisboa) and by the Department of Veterinary Medicine, Università degli Studi di Bari, Italy. AMA held a FCT PhD Research Grant, $\mathrm{SFRH} / \mathrm{BD} / 85427 / 2012$. The funders had no role in the design of the study, collection, analysis, interpretation of data or in writing the manuscript.

Availability of data and materials

All data generated or analysed during the study are included in the article.

\section{Authors' contributions}

AMA conceived the study, performed analysis and drafted the manuscript; $\mathrm{CL}$ conducted clinical examination, sample collection and revised the manuscript; MSL and VC designed the study, performed molecular and data analysis and revised the manuscript; SR and GC performed molecular analysis; LMC reviewed the manuscript; LC helped conceive the study, analysed data and revised the manuscript; DO conceived the study and reviewed the manuscript. All authors read and approved the final manuscript.

\section{Competing interests}

The authors declare that they have no competing interests.

\section{Consent for publication}

Not applicable.

\section{Ethics approval}

All clinical procedures were in accordance with Portuguese (Decree-Laws no. 314/2003 and no. 113/2013) and European legislation for the protection of animals.

\section{Author details}

${ }^{1}$ CIISA, Faculdade de Medicina Veterinária, Universidade de Lisboa, Lisbon, Portugal. ${ }^{2}$ Hospital Parkview Pet Center - Veterinary Clinic, Doha, Qatar. ${ }^{3}$ Dipartimento di Medicina Veterinaria, Università degli Studi di Bari, Bari, Italy. ${ }^{4}$ Istituto Zooprofilattico Sperimentale delle Venezie, Legnaro, Padova, Italy. ${ }^{5}$ Department of Veterinary Sciences, School of Agrarian and Veterinary Sciences, University of Trás-os-Montes e Alto Douro (UTAD), Vila Real, Portugal.

Received: 7 April 2017 Accepted: 11 June 2017

Published online: 20 June 2017

\section{References}

1. Otranto D, Dantas-Torres F, Breitschwerdt EB. Managing canine vector-borne diseases of zoonotic concern: part one. Trends Parasitol. 2009;25:157-63.

2. ESCCAP (European Scientific Counsel Companion Animal Parasites), 2012. ESCCAP Guideline 5 - Control of vector-borne diseases in dogs and cats ( $2^{\text {nd }}$ ed.). http://www.esccap.org/uploads/docs/ih38c2d6_ESCCAP_ Guidelines_GL5 010ct2012.pdf. Accessed 17 Mar 2017.

3. Solano-Gallego L, Baneth G. Babesiosis in dogs and cats - expanding parasitological and clinical spectra. Vet Parasitol. 2011;181:48-60.

4. Sainz Á, Roura X, Miró G, Estrada-Peña A, Kohn B, Harrus S, et al. Guideline for veterinary practitioners on canine ehrlichiosis and anaplasmosis in Europe. Parasit Vectors. 2015;8:75. 
5. Solano-Gallego L, Caprì A, Pennisi MG, Caldin M, Furlanello T, Trotta M. Acute febrile illness is associated with Rickettsia spp. infection in dogs. Parasit Vectors. 2015;8:216.

6. Otranto D, Napoli E, Latrofa MS, Annoscia G, Tarallo VD, Greco G, et al. Feline and canine leishmaniosis and other vector-borne diseases in the Aeolian Islands: Pathogen and vector circulation in a confined environment. Vet Parasitol. 2017;236:144-51.

7. Baneth G, Bourdeau P, Bourdoiseau G, Bowman D, Breitschwerdt E, Capelli $\mathrm{G}$, et al. Vector-borne diseases - constant challenge for practicing veterinarians: recommendations from the CVBD World Forum. Parasit Vectors. 2012;5:55.

8. Otranto D, Dantas-Torres F, Brianti E, Traversa D, Petric D, Genchi C, et al. Vector-borne helminths of dogs and humans in Europe. Parasit Vectors. 2013;6:16

9. Colwell DD, Dantas-Torres F, Otranto D. Vector-borne parasitic zoonoses: emerging scenarios and new perspectives. Vet Parasitol. 2011;182:14-21.

10. Otranto D, Cantacessi C, Pfeffer M, Dantas-Torres F, Brianti E, Deplazes P, et al, The role of wild canids and felids in spreading parasites to dogs and cats in Europe. Part I: Protozoa and tick-borne agents. Vet Parasitol. 2015;213:12-23.

11. Morchón R, Carretón E, González-Miguel J, Mellado-Hernández I. Heartworm disease (Dirofilaria immitis) and their vectors in Europe - new distribution trends. Front Physiol. 2012;3:196.

12. Øines $\varnothing$, Storli $K$, Brun-Hansen $H$. First case of babesiosis caused by Babesia canis canis in a dog from Norway. Vet Parasitol. 2010;171:350-3.

13. de Marco MDMF, Hernández-Triana LM, Phipps LP, Hansford K, Mitchell ES, Cull B, et al. Emergence of Babesia canis in southern England. Parasit Vectors. 2017;10:241.

14. Qatar Census, 2010. Available at: https://www.qsa.gov.qa/QatarCensus/ Economic.aspx. Accessed 16 Mar 2017.

15. Inokuma H, Okuda M, Ohno K, Shimoda K, Onishi T. Analysis of the $18 \mathrm{~S}$ rRNA gene sequence of a Hepatozoon detected in two Japanese dogs. Vet Parasitol. 2002;106:265-71.

16. Harrus S, Perlman-Avrahami A, Mumcuoglu KY, Morick D, Eyal O, Baneth G. Molecular detection of Ehrlichia canis, Anaplasma bovis, Anaplasma platys, Candidatus Midichloria mitochondrii and Babesia canis vogeli in ticks from Israel. Clin Microbiol Infect. 2011:17:459-63.

17. Otranto D, Brianti E, Dantas-Torres F, Weigl S, Latrofa MS, Gaglio G, et al. Morphological and molecular data on the dermal microfilariae of a species of Cercopithifilaria from a dog in Sicily. Vet Parasitol. 2011;182:221-9.

18. Ravagnan S, Carli E, Piseddu E, Da Rold G, Porcellato E, Zanardello C, et al. Prevalence and molecular characterization of canine and feline hemotropic mycoplasmas (hemoplasmas) in northern Italy. Parasit Vectors. 2017;10:132.

19. Willi B, Meli ML, Lüthy R, Honegger H, Wengi N, Hoelzle LE, et al. Development and application of a universal Hemoplasma screening assay based on the SYBR green PCR principle. J Clin Microbiol. 2009;47:4049-54.

20. Choi YJ, Jang WJ, Ryu JS, Lee SH, Park KH, Paik HS, et al. Spotted fever group and typhus group rickettsioses in humans, South Korea. Emerg Infect Dis. 2005;11:237-44.

21. Olmeda AS, Armstrong PM, Rosenthal BM, Valladares B, del Castillo A, de Armas F, et al. A subtropical case of human babesiosis. Acta Trop. 1997;67:229-34

22. Casati S, Sager H, Gern L, Piffaretti JC. Presence of potentially pathogenic Babesia sp. for human in Ixodes ricinus in Switzerland. Ann Agric Environ Med. 2006:13:65-70.

23. Larkin MA, Blackshields G, Brown NP, Chenna R, McGettigan PA, McWilliam $H$, et al. Clustal W and Clustal X version 2.0. Bioinformatics. 2007:23:2947-8.

24. Ghazisaeedi F, Atyabi N, Zahrai Salehi T, Gentilini F, Ashrafi Tamai I, Akbarein $H$, et al. A molecular study of hemotropic mycoplasmas (hemoplasmas) in cats in Iran. Vet Clin Pathol. 2014;43:381-6.

25. Aktas M, Özübek S, Altay K, Ipek ND, Balkaya I, Utuk AE, et al. Molecular detection of tick-borne rickettsial and protozoan pathogens in domestic dogs from Turkey. Parasit Vectors. 2015;8:157.

26. Sacchini F, Cessford RJ, Robinson BM. Outbreak of canine monocytic ehrlichiosis in Saudi Arabia. Vet Clin Pathol. 2007;36:331-5.

27. Botros BAM, Elmolla MS, Salib AW, Calamaio CA, Dasch GA, Arthur RR. Canine ehrlichiosis in Egypt: sero-epidemiological survey. Onderstepoort J Vet Res. 1995;62:41-3.

28. Baneth G, Waner T, Koplah A, Weinstein S, Keysary A. Survey of Ehrlichia canis antibodies among dogs in Israel. Vet Rec. 1996;138:257-9.

29. Levi O, Waner T, Baneth G, Keysary A, Bruchim Y, Silverman J, et al. Seroprevalence of Anaplasma phagocytophilum among healthy dogs and horses in Israel. J Vet Med B Infect Dis Vet Public Health. 2006;53:78-80.
30. Baneth G, Harmelin A, Presentey BZ. Hepatozoon canis infection in two dogs. J Am Vet Med Assoc. 1995;206:1891-4.

31. Wenyon CM. Oriental sore in Bagdad, together with observations on a gregarine in Stegomyia fasciata, the haemogregarine of dogs and the flagellates of house flies. Parasitology. 1911;4:273-343.

32. Fahmy MAM, Arafa MS, Mandour AM. Further notes on the life history of Hepatozoon canis (James, 1905). J Egypt Soc Parasitol. 1977;7:113-22.

33. Irwin PJ, Hutchinson GW. Clinical and pathological findings of Babesia infection in dogs. Aust Vet J. 1991;68:204-9.

34. Penzhorn BL, Schoeman T, Jacobson LS. Feline babesiosis in South Africa: a review. Ann NY Acad Sci. 2004:1026:183-6.

35. Dantas-Torres F, Latrofa MS, Annoscia G, Giannelli A, Parisi A, Otranto D. Morphological and genetic diversity of Rhipicephalus sanguineus sensu lato from the New and Old Worlds. Parasit Vectors. 2013;6:213.

36. Schuster RK, Thomas K, Sivakumar S, O'Donovan D. The parasite fauna of stray domestic cats (Felis catus) in Dubai, United Arab Emirates. Parasitol Res. 2009;105:125-34.

\section{Submit your next manuscript to BioMed Central and we will help you at every step:}

- We accept pre-submission inquiries

- Our selector tool helps you to find the most relevant journal

- We provide round the clock customer support

- Convenient online submission

- Thorough peer review

- Inclusion in PubMed and all major indexing services

- Maximum visibility for your research

Submit your manuscript at www.biomedcentral.com/submit

) Biomed Central 